\title{
Distance (Remote) Learning: on the issue of its efficiency and accessibility
}

\author{
A. G. Kliucharev ${ }^{1,2}$
}

${ }^{1}$ Institute of Sociology, Federal Scientific Research Center for Theoretical and Applied Sociology, RAS, 24/35, building 5 Krzhizhanovsky Str., Moscow 117218, Russian Federation

2Department of Philosophy, Sociology, Political Science after G.S. Arefyeva, Moscow Power Engineering Institute, 14 Krasnokazarmennaya St., 111250 Moscow, Russian Federation

DOI: $10.18255 / 2412-6519-2020-3-274-285$

Research Article

Full text in Russian

The issue of the feasibility of a significant increase in the share of distance (remote) learning in modern higher education and a reduction in-side (auditorium) classes is discussed. The following factors were taken into account: the quality of education, its accessibility, the specifics of distance learninf, economic benefits, the personification of training courses, the monitoring and evaluation of the acquisition of knowledge, the awareness of the possibilities of distance learning, the attitude of the faculty stuff and university administrations towards them. It is shown that distance learning provides high-quality education, personifies the educational process, most fully implements the key-principle of LLL - "learn when, how and where you feel comfortable." Based on the internal needs of universities - the solution of personnel problems, the optimization of the educational process, the desire to improve the quality of education and its competitiveness - the possible benefits that stimulate the use of online courses in educational programs are indicated. The role of informal distance learning, which can become an effective means of educational work in higher school, is studied. It becomes an effective mean of socializing not only students, but other youth groups (for example, blogging community). Already today group self-education is actively developing, especially within the framework of informal network communities, public and religious associations. In these socio-political processes, universities can occupy an important domain that society initially assigned to them and which they more or less successfully mastered along while their entire history.

Keywords: digital technologies; distance education; online courses; non-formal education; personification of training courses; the benefits of distance learning; teacher functions

\section{INFORMATION ABOUT THE AUTHORS}

\author{
Kliucharev Grigori A. $\quad$ E-mail: kliucharev@mail.ru \\ Doctor of Philosophy, Head of the Center for Sociology of Education and \\ Science, Professor
}

For citation: Kliucharev G. A. Distance (Remote) Learning: on the issue of its efficiency and accessibility // Social'nye i gumanitarnye znanija. 2020. Vol. 6, No 3. P. 274-285. (in Russ.) 


\title{
Дистанционное (удаленное) обучение: к вопросу об эффективности и доступности
}

\author{
Г. А. Ключарев 1,2
}

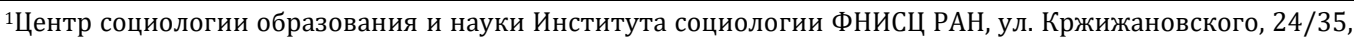
к. 5, Москва, 117218, Российская Федерация

${ }^{2}$ Кафедра философии, социологии, политологии им. Г. С. Арефьевой, Национальный исследовательский университет - Московский энергетический институт, ул. Красноказарменная, 14, Москва, 111250, Российская Федерация
\end{abstract}

DOI: $10.18255 / 2412-6519-2020-3-274-285$

удК 316.1

Научная статья

Полный текст на русском языке

Обсуждается вопрос о целесообразности значительного увеличения доли дистанционного (удаленного) обучения в современной высшей школе и сокращения аудиторных занятий. Во внимание приняты следующие факторы: качество образования, его доступность, специфика дистанционного образования, экономические выгоды, персонификация учебных курсов, контроль и оценка усвоения знаний, информированность о возможностях дистанционного обучения, отношение к нему профессорско-преподавательского состава и администраций вузов. Показано, что дистанционное обучение обеспечивает качественное образование, персонифицирует учебный процесс, наиболее полно реализует принцип непрерывного образования - «учись когда, как и где тебе удобно». Исходя из внутренних потребностей университетов - решение кадровых проблем, оптимизация учебного процесса, желание улучшить качество образования и его конкурентоспособность - указаны возможные выгоды, которые стимулируют использование онлайн-курсов в образовательных программах. Изучена роль неформального дистанционного обучения, которое может стать эффективным средством воспитательной работы в высшей школе. Оно становится эффективным средством социализации не только студенческой, но других групп молодежи (например, блоговые коммуникации и сообщества). Уже сегодня активно развивается групповое самообучение, особенно в рамках неформальных сетевых сообществ, общественных и религиозных объединений. В этих социально-политических процессах университеты могут занять важную нишу, которую им изначально отводило общество и которую они более или менее успешно осваивали всю свою историю.

Ключевые слова: цифровые технологии; дистанционное образование; онлайн-курсы;

неформальное образование; персонификация учебных курсов; выгоды дистанционного обучения; функции преподавателя

\section{ИНФОРМАЦИЯ ОБ АВТОРАХ}

Ключарев Григорий Артурович

E-mail: kliucharev@mail.ru

Доктор философских наук, руководитель Центра социологии

образования и науки, профессор МЭИ

Для цитирования: Ключарев Г. А. Дистанционное (удаленное) обучение: к вопросу об эффективности и доступности // Социальные и гуманитарные знания. 2020. Том 6, № 3. С. 274-285.

(C) Ключарев Г. А., 2020

Статья открытого доступа под лицензией СC BY-NC-ND (http://creativecommons.org/licenses/by-nc-nd/4.0/) 


\section{Актуальность}

Очевидно, что современные российские университеты по своей структуре и функционалу недалеки от гумбольдтианской модели классического университета с его сложной иерархией профессоров, преподавателей, администраций, акцентом на лекционные и семинарские занятия, строгим контролем учебного процесса в виде зачетов и экзаменов. Однако, острая конкурентная борьба между высшими учебными заведениями за контингент (новых абитуриентов и студентов) и бюджетные трансферты заставляет искать новые формы учебного процесса, результативность которых проявляется прежде всего в хорошем трудоустройстве выпускников и качественном оказании образовательной услуги. Современные цифровые технологии радикально преобразуют нынешний университетский ландшафт. Используя метафору известного французского философа и социолога знания Ж. Лиотара, можно сказать, что благодаря развитию цифровых информационных технологий «Эра профессора» заканчивается и наступает эра дистанционного обучения.

\section{Дистанционное (удаленное) обучение ${ }^{1}$ - новый этап развития образования}

Дистанционное обучение характеризуется несколькими важными признаками. Первый - это существенное сокращение количества аудиторных занятий и, как следствие, уменьшение времени непосредственного взаимодействия преподавателя и студентов. Второй - на авансцену выходит цифровое устройство, обеспечивающее доступ и работу в сети Интернет или в локальных сетях. Третий признак особенно важен - студенты получают возможность самостоятельно (в определенных пределах, конечно) определять содержание изучаемого материала [1]. В этом смысле дистанционное обучение можно отнести к форме самообразования [2], и именно этим определяется довольно «прохладное» отношение к нему многих работников высшей школы. Конечно, вопрос стоит гораздо шире: что является источником знаний и кто определяет формы процесса познания и учения. Самообразование у нас никогда особенно не приветствовалось. Более столетия назад в своей записке государю о воскресных народных школах (основателем которых считается знаменитый хирург Н. Пирогов) князь В. Долгоруков указывал: «Правительство не может допустить, чтобы половина народонаселения была обязана своим образованием не государству, а себе или частной благотворительности какого-либо отдельного сословия» [3]. Понятно, что такая позиция сохранилась в значительной степени и до настоящего времени. Затронула она, конечно, и высшую школу.

Сегодняшнее во многом «настороженное» отношение к дистанционному обучению обусловила еще советская педагогика, рассматривавшая самообразование как дополнительную форму учебного процесса, которая может ограниченно применяться для «сшивки» разрозненных учебных материалов в рамках различных курсов

\footnotetext{
${ }^{1}$ Под дистанционным (удаленным) профессиональным образованием (ДО) мы понимаем учебный процесс, который обеспечивает формальное и неформальное информационное взаимодействие (в том числе, с помощью искусственного / машинного интеллекта и самосовершенствующихся учебных программ) и при этом исключает прямую (очную) коммуникацию всех участников процесса вне зависимости от их статуса и места в университетской иерархии.
} 
или же для избирательного углубления знаний в зависимости от потребностей участников учебного процесса [4].

Тем не менее появление и широкое распространение цифровых технологий изменило правила игры. Социально-экономические выгоды использования дистанционного обучения потребовали серьезного пересмотра организации учебного процесса в высшей школе [5]. По сути, речь идет о возникновении нового этапа развития образования. Соответственно, постепенно формируется такой тип учащегося, который сознательно управляет своей учебной деятельностью и вправе требовать оказания образовательной (особенно платной) услуги, которая видится ему наиболее привлекательной, качественной и полезной.

\section{Отношение к дистанционному обучению}

Приведем некоторые данные об отношении граждан к дистанционному обучению, как к профессиональному, так и к досуговому르. Отвечая на вопрос о своих предпочтениях в сфере культуры и саморазвития, 53 \% респондентов отметили, что им нравится обучаться с помощью компьютера. При этом группы тех респондентов, кто воспринимает цифровые технологии как источник своего культурного развития, и тех, кто считает самообразование прагматической ценностью, способом карьерного роста, в значительной мере пересекаются: среди «прагматиков» подавляющее большинство опрошенных (89 \%) являются одновременно и «романтиками», для которых компьютер - источник саморазвития. По отношению к «романтикам» и «прагматикам» не выступают антиподом и «традиционалисты»- сторонники третьей модели - получение формального дистанционного образования. В группах респондентов с более высоким уровнем формального образования, как правило, больше доли сторонников первых двух форм неформального дистанционного образования. Таким образом, на практике, во всяком случае применительно к сегодняшней ситуации, три формы дистанционного образования оказываются взаимодополняющими. При этом около половины респондентов (48,5\%) уже сегодня с помощью дистанционных цифровых технологий самостоятельно следят за литературой по специальности, регулярно посещают профильные сетевые ресурсы, участвуют в вебинарах, осваивают новые профессиональные навыки и учатся на онлайн-программax.

Респонденты отличаются друг от друга не столько своей приверженностью к той или иной форме образования, сколько большей или меньшей склонностью к получению образования вообще. Исходя из этой логики, можем выделить три сильно различающиеся по объему группы: 7 \% - респонденты с сильной мотивацией к образованию с помощью цифровых технологий (с высшим и незаконченным высшим образованием, воспринимающие образование как общекультурную и инструментальную ценность); $57 \%$ - опрошенные со средней склонностью к образованию (посередине между предыдущей и последующей группами); 36 \% - респонденты с низкой мотивацией. Это люди с неполным средним, средним и средним специальным образованием, относящиеся к образованию равнодушно или отрицательно и не

\footnotetext{
${ }^{1}$ За эмпирическую основу приняты данные второй волны (2017 г.) исследования ИС РАН по проекту РНФ № 1428-00218 «Динамика социальной трансформации современной России в социально-экономическом, политическом, социокультурном и этнорелигиозном контекстах»; общероссийская репрезентативная выборка - 4000 респондентов, руководитель проекта - акад. М. К. Горшков
} 
ставящие своей задачей повысить профессиональный уровень. Мотивация к дистанционному образованию в целом выше у женщин (чем у мужчин), у молодежи (по сравнению со средним и тем более старшим поколениями), у жителей мегаполисов (на фоне жителей областных центров и особенно районных центров и сел), у тех, кто никогда не состоял в браке (по сравнению с женатыми и разведенными, а также в особенности вдовыми). В группе респондентов с высокой склонностью к «цифровой» учебе процент работающих выше, чем в двух других группах: не работает в первой группе каждый пятый, во второй и третьей - каждый третий. Люди с высокой склонностью к образованию имеют больше шансов стать предпринимателями или руководителями разного уровня на предприятии или в учреждении, по сравнению с респондентами со средней мотивацией, при том что у опрошенных с низкой мотивацией кучебе эти шансы близки к нулю. Практически равны нулю для третьей группы опрошенных и возможности работать специалистом на должности, предполагающей высшее образование, во второй группе такой работой заняты $23 \%$, тогда как в первой группе свыше половины - 58 \%. Отметим также, что респонденты, высоко мотивированные на учебу, практически не пополняют ряды рабочих. Высокая склонность к компьютерному образованию не только открывает возможности заниматься ответственной и интересной работой, но и позволяет при меньшем количестве рабочих часов получать более высокие доходы, как личные, так и на каждого члена семьи.

Положение на социальной лестнице семей респондентов также зависит от их склонности к образованию. Группа с низкой мотивацией за последние годы больше других пострадала (по собственным оценкам) от финансового кризиса, санкций, но надеется в ближайшее время вернуть утраченные позиции. Группы со средней и тем более высокой мотивацией к самообразованию не только потеряли меньше в сложных условиях, но и рассчитывают через пять лет занять более статусное место в обществе, чем было прежде.

Согласно этим прогнозам респондентов в отношении собственного будущего, в России ожидается углубление социального неравенства, и место человека на общественной лестнице во многом будет определяться его склонностью к непрерывному образованию и в первую очередь в дистанционной форме. Подтверждают этот прогноз и оценки россиянами собственного материального положения в динамике (плюс-минус год). Хотя за прошедший накануне опроса год материальный статус в каждой группе «скорее понизился, чем повысился», первая (высокомотивированная) группа пострадала не столь существенно (ухудшения отмечают 35 \%, улучшения 18 \%). Для сравнения: эти же показатели для третьей группы (низкомотивированные респонденты) составляют 61 \% (изменение своего материального положения к худшему) и только $6 \%$ видят позитивные сдвиги. Оценки собственных материальных перспектив на ближайший год в трех исследуемых группах, очевидно, связаны с вероятностью оказаться безработным. Так, полагают, что маловероятно или даже исключено потерять работу, свыше половины опрошенных в первой группе (56 \%), во второй группе - треть (35 \%), в третьей группе - один из пяти (18\%).

Группы респондентов с разной склонностью к цифровому образованию различаются не только по их отношению к труду, материальному и социальному статусу, но и по структуре свободного времени. Исследование выявило, что чем выше мотивация респондентов к учебе, тем разнообразнее их досуг. И это разнообразие оказывается доступным не только благодаря более высоким доходам в первой группе, но и за счет рационального использования свободного времени. Группа с высокой 
мотивацией гораздо реже «просто отдыхает», расслабляется, в этой группе «ничегонеделанием» в свободное время обычно занимаются только $21 \%$ при 52 и 58 \%\% в группах со средней и низкой мотивацией.

\section{Дистанционное обучение и качество образования}

Качество образования - предельно широкое понятие, содержание которого значительно варьируется от контекста [6]. Если оставить в стороне общее образование, которое в основном воспроизводит существующую социальную структуру, то содержание профессионального образования определяется ситуацией на рынке труда, а также спросом на те или иные профессии как со стороны работодателей, так и со стороны самих учащихся (студентов и их родителей). Качественное профессиональное образование стоит связать с успешностью вхождения выпускника на рынок труда, фактом трудоустройства по полученной специальности и в конечном счете размером вознаграждения за свой труд [7]. Такой прагматический подход вполне соответствует теории человеческого капитала, когда результаты обучения в итоге конвертируются в материальные и иные активы конкретного человека.

Понятно, что качество учебных программ и образовательных институций (а в иной терминологии - качество и ассортимент образовательных услуг) существенно варьируется и зависит от очень многих факторов, которые в своей совокупности обеспечивают доступность и, соответственно, неравенство в доступности образования [8]. На онтологическую природу образовательного неравенства указывают многие исследователи [9; 10]. Это означает, что благодаря существующему неравенству (экономическому, демографическому, интеллектуальному и др.) качественным должно быть любое образование, которое доступно конкретному человеку в конкретной ситуации. Но под качеством будет всякий раз пониматься успешность адаптации к конкретной микросреде.

Сказанное имеет прямое отношение к способам коммуникации участников учебного процесса. В модели классического университета, да и любого учреждения высшей школы, как уже кратко отмечалось выше, с необходимостью доминирует аудиторно-лекционная система организации занятий, которая требует личного и одновременного присутствия в определенном месте ограниченного числа людей. Лекционные и поточные аудитории организованы, как правило, в виде амфитеатра, в центре которого располагается специально оборудованное место для лектора или профессора. Лекция обычно проходит в форме монолога выступающего на протяжении полутора часов. Скорость изложения материала определяется интуитивно читающим лекцию. Обратная связь со слушателями отсутствует. Частично эти недостатки потом исправляются во время практических и семинарских занятий. Учебный процесс предельно формализован: контрольные недели, промежуточные аттестации, зачеты и экзамены - которые создают видимость более или менее успешного усвоения материала. Неформальная составляющая, которая связана с коммуникацией вне учебного процесса, обращению к иным источникам информации помимо рекомендованных кафедрой или преподавателем, не засчитывается при выставлении итоговых оценок.

Эти «особенности» (некоторые называют их недостатками) классического учебного процесса в высшей школе успешно преодолеваются дистанционным обучением, в рамках которого рождаются новые образовательные технологии. Возьмем, к примеру, блогосферу, в которой распространяются знания, составляющие предмет 
обучения. Очевидно, что студенты, вне зависимости от того, в какой стране мира они находятся, гораздо охотнее примут участие в видеоблоге нобелевского лауреата по экономической географии Пола Кругмана (Paul Krugman) ${ }^{1}$, чем станут слушать монотонную лекцию, содержание которой не меняется годами. В этой связи приведем отрывок из интервью, которое нам дал аспирант одного из провинциальных вузов: «На первом курсе мы слушали лекции по общей физике, лектор пользовался своими конспектами, явно подготовленными несколько лет назад. На третьем курсе электродинамику читал тот же самый лектор. При этом он пользовался отдельными листочками-страницами из учебника, написанного им лет 15 назад. На пятом курсе теоретическую физику читал тот же преподаватель, а пожелтевшие листочки из учебника были наклеены на листы формата $A 4 »^{2}$.

Радикальная персонификация учебного процесса («учись когда, где и как тебе удобно») - это, по сути, основной принцип концепции непрерывного образования $[11 ; 12]$ - очень важный элемент современного онлайн-образования. Реализуется она в рамках Эмпорийской модели. Десятки университетов по всему миру (включая частные мегапроекты типа академии Салмана Хана ${ }^{3}$ ) открыли на территории своих студенческих городков большие компьютерные классы (на 200-500 и более человек), которые работают круглосуточно. Здесь можно войти во внутреннюю сеть университета, которая обеспечивает онлайн-доступ к видео- и аудиоматериалам, необходимым для выполнения учебной программы. Часто под такие помещения используются бывшие супермаркеты, число которых устойчиво сокращается по мере развития интернет-торговли [13]. Отсюда и происходит название модели.

Персонификация учебного процесса выражается и в адекватности выставляемой оценки - степени усвоенных знаний и приобретенных компетенций. Слабые места очной формы контроля в виде зачетов и экзаменов хорошо известны: это субъективность подхода, различные требования экзаменаторов (разрешено ли пользоваться конспектами или, не дай бог, смартфоном), общая стрессовая обстановка и т. д. Напротив, современные курсы и используемые софт-приложения позволяют зафиксировать, какие материалы требуют более одного просмотра, как и где ставится пауза, возврат к уже пройденному. При этом гарантируется 100 \%-ная идентификация личности учащегося как при прохождении промежуточной аттестации, так и при сдаче финального экзамена по курсу [14].

Все эти элементы дистанционного обучения, в котором активное участие принимает специальный софт, называют машинным обучением. Благодаря этому накапливается больщая база данных по реальной картине учебного процесса. Она позволяет не только существенно повысить эффективность обучения, но и отслеживать

\footnotetext{
${ }^{1}$ Paul Krugmann. Он-лайн класс по экономической географии. URL: https://www.masterclass.com/classes/paulkrugman-teaches-economics-and-society (дата обращения 15.05.2020).

${ }^{2}$ Исследование «Непрерывное образование и наукоемкие технологии: институты и практики взаимодействия» № 16-18-10420 при поддержке РНФ (2016-2018 гг.), интервью № 61.

${ }^{3}$ Академия Салмана Хана. Главная страница сайта. URL: https://www.khanacademy.org/ (дата обращения 15.05.2020).
} 
и анализировать физиологические (частота пульса, уровень давления) и вазомоторные (выражение лица) показатели - в состоянии ли учащийся воспринимать материал, скучно ли ему и т. д.

Выше уже отмечалось, что дистанционное обучение может проходить в виде неформального образования, главным образом как самообразования или как части формального в институализированной среде учебных заведений. Ведущие российские университеты ${ }^{1}$ в последние годы выстроили институциональную практику включения онлайн-курсов в учебный процесс. Это могут быть курсы как собственной разработки, так и других учебных заведений, включая зарубежные. Учебные курсы, реализуемые в цифровом формате, можно использовать как полноценную замену учебных дисциплин, входящих в учебные планы.

Обучение может быть модульным, где предусмотрены контрольные вопросы и налажена постоянная обратная связь; может проходить в виде записанных специалистами непродолжительных лекций-монологов, а чаще - диалогов, как это сделано, к примеру, на философском университете БГУ им. И. Канта (Калининград) ${ }^{2}$. Конечно, имеет значение, насколько полно при разработке курсов учитываются требования Федеральных государственных образовательных стандартов (ФГОСы). «Пионером» в этой работе выступает русскоязычная национальная платформа «Открытое образование», созданная Минобрнауки РФ и обеспечивающая внутреннюю экспертизу и сертификацию курсов.

\section{Основания и технология использования онлайн-курсов}

Существуют две основные модели создания и использования онлайн-курсов: собственные разработки и обращение к сторонним ресурсам. Причем второй путь может быть предпочтительнее, если университет-разработчик имеет многолетний опыт разработки программ, располагает квалифицированными кадрами, а сами программы прошли установленную сертификацию. В этом случае рекомендуется заключать договоры о сетевой форме реализации дистанционного обучения между университетами. Предполагается, что «покупка» происходит на институциональном уровне и выбор совершается университетом-реципиентом в целом. Далее университет-реципиент включает в свой учебный план приобретенный онлайн-курс (несколько курсов), а студенты обязаны изучить именно этот учебный курс(ы). По завершении университет-реципиент засчитывает результаты освоения курса.

Возможен и другой путь, когда студент университета-реципиента самостоятельно выбирает онлайн-курс, который согласовывается с преподавателем и кафедрой. После прохождения такого курса преподаватель выставляет зачет и фиксирует выполнение учебного плана.

\footnotetext{
${ }^{1}$ К примеру:

- Томский государственный университет. Страница обучающих курсов на официальном сайте: https://ido.tsu.ru/ (дата обращения 15.05.2020);

- НИУ-ВШЭ, Страница обучающих курсов на официальном сайте: https://electives.hse.ru/mooc_students (дата обращения 15.05.2020);

- Уральский Федеральный университет имени Первого президента России Б.Н.Ельцина Страница обучающих курсов на официальном сайте: http://openedu.urfu.ru/ (дата обращения 15.05.2020);

- Ярославский государственный университет им. П.Г.Демидова, Страница обучающих курсов на официальном сайте: https://moodle.uniyar.ac.ru/ (дата обращения 15.05.2020).

2 Курс он-лайн лекций по философии науки и техники БГУ им. И. Канта https://www.youtube.com/playlist?list=PL48Q51pndTVkR-6uBcjNqX354iXx4yPXT (дата обращения 15.05.2020)
} 
Здесь стоит обратить внимание на то, что разработка и продажа обучающих онлайн-материалов может стать важной статьей дохода любого университета. В международной практике англоязычные курсы помогают в обучении миллионов студентов по всему миру и приносят университетам-разработчикам и провайдерам курсов доходы, сопоставимые с выгодами от основной (аудиторной) деятельности. Русскоязычный сегмент этого образовательного рынка несколько скромнее, но с учетом студентов на постсоветском пространстве может достигать нескольких сотен тысяч человек. Для разработки русскоязычных курсов любой университет может приглашать известных специалистов - научных селибрити, имя и авторитет которых станут наилучшей визитной карточкой и рекламой университета.

Вопрос о включении онлайн-курсов в учебные программы университетов решается на уровне ректоратов, факультетов, кафедр [15]. Основная сложность это учет нагрузки преподавателя, студенты которого используют эту форму обучения. Как известно, нагрузка преподавателя исчисляется в основном часами аудиторной работы. Если онлайн-курсы включены в учебные планы, то некоторые администрации считают, что нагрузка преподавателя уменьшается и есть риск потери ставок. Но передовые университеты решают эту проблему за счет увеличения доли НИР в структуре времени занятости преподавателя, у которых появляется больше времени и сил для качественной научной работы и подготовки публикаций в рейтинговых журналах. Тем не менее информированность о возможностях и выгодах дистанционного обучения остается достаточно низкой. Ректораты не спешат признавать, что использование качественных онлайн-курсов повышает уровень преподавания, экономит фонд заработной платы профессорско-преподавательского состава, не говоря уже об уменьшении размеров коммунальных платежей и возможностях сокращения (высвобождения) аудиторного фонда.

Назовем возможные выгоды, которые могут стимулировать использование онлайн-курсов в образовательных программах университетов, исходя из внутренних потребностей: решение кадровых проблем, оптимизация учебного процесса, желание улучшить качество образования и его конкурентоспособность [16].

1. Университет не может обеспечить реализацию одной или нескольких обязательных дисциплин (в том числе т. н. «длинной» дисциплины) или дисциплин вариативной части в связи с отсутствием преподавателя требуемой квалификации либо значительными издержками по его найму.

2. Университету необходимо увеличить вариативность предлагаемых курсов и обеспечить студентам возможность выбора индивидуальных траекторий обучения, не увеличивая при этом издержки на найм дополнительных преподавателей.

3. Университету необходимо ликвидировать разницу в имеющихся знаниях и компетенциях у студентов (например, иностранных либо поступивших в магистратуру из других университетов). В этом случае необходимы адаптационные курсы, которые используются точечно (персонально), не требуя средств на формирование неэффективных малых групп.

4. Университет хочет решить задачу развития надпредметных компетенций студентов (работа в разнородных группах, решение коллективных задач, погружение в чужеродную неизвестную среду, способность к самоорганизации и самоконтролю и пр.) в ходе учебной деятельности.

5. Университет приветствует использование нескольких источников при обучении для формирования у студентов более объемного знания, способности к сопоставлению, развитию критического мышления. 
6. Университет хочет усилить привлекательность своих образовательных программ за счет использования брендов сильных российских и зарубежных университетов, онлайн-курсы которых будут изучаться студентами (что может быть отражено в приложении к диплому и станет привлекательным для работодателей, родителей абитуриентов), при условии заключения с этими университетами договора о сетевой форме реализации образовательных программ.

7. Университет планирует увеличение численности абитуриентов и иногородних студентов за счет тех, кто по разным причинам (наличие хорошей работы, уход за родителями и т. д.) не может постоянно находиться на территории студенческого городка.

8.Университету необходимо реструктурировать нагрузку ППС, высвободив часть времени преподавателей для научной работы, не увеличивая штатную численность ППС.

9. Университету необходимо сократить штатную численность ППС, не уменьшая при этом качество образовательных программ и предложений студентам.

10. Есть еще один аргумент, который идет поверх этого списка и который очень хорошо узнали практически все преподаватели и студенты во время второго семестра 2019/2020 учебного года. Речь идет о самоизоляции и всеобщем переходе на дистанционную (удаленную) форму организации занятий.

Перечисленных аргументов вполне достаточно, на наш взгляд, чтобы администрации университетов и вузов стали более внимательны к дистанционному (удаленному) обучению.

Теперь посмотрим, как обстоит дело с нормативной и правовой базой, регулирующей деятельность системы высшего образования этой части. Оказывается, что никаких запретов на использование университетами онлайн-курсов (как самостоятельно разработанных, так и онлайн-курсов других университетов) не существует. Более того, приоритетный проект «Современная цифровая образовательная среда в Российской Федерации» ${ }^{1}$ в явном виде нацеливает университеты на расширение использования качественных учебных онлайн-курсов в образовательном процессе. Совокупность документов, которая позволяет делать выводы о возможности использовать онлайн-курсы, следующая:

Федеральный закон «Об образовании в Российской Федерации» от 29.12.2012 № 273-Ф32 ${ }^{2}$ содержит описание возможных способов интеграции ресурсов разных университетов при организации учебного процесса (т. н. сетевая форма реализации образовательных программ); использования в учебном процессе дистанционных образовательных технологий и электронного обучения; компетенций образователь-

\footnotetext{
${ }^{1}$ Паспорт приоритетного проекта «Современная цифровая образовательная среда в Российской Федерации». Утвержден Президиумом совета при Президенте Российской Федерации по стратегическому развитию и приоритетным проектам (протокол от 25 октября 2016 г. N 9) // Правительство России. URL: http://government.ru/media/files/8SiLmMBgjAN89vZbUUtmuF5IZYfTvOAG.pdf (дата обращения: 16.05.2020).

2 Федеральный закон «Об образовании в Российской Федерации» от 29.12.2012 № 273-Ф3 // Законодательство Российской Федерации. Сборник основных федеральных законов РФ. URL: https://fzrf.su/zakon/ob-obrazovanii273-fz/ (дата обращения: 16.05.2020). Статьи 13 (п.п. 1, 2), 15 (п.п. 1, 2), 16 (п.п. 1, 2, 4), 28 (п.п. 1, 2, 3(6), 3(12)), 34 (п. 1(4), 1(5), 1(6), 1(7), 1(24)), 47.
} 
ных организаций по формированию образовательной программы и выбору технологий и методов обучения; прав студентов осваивать учебные дисциплины в других университетах, предъявлять на зачет внешние результаты, участвовать в академической мобильности; свободы выбора преподавателями форм и методов обучения, формирования программ дисциплин.

Далее можно сослаться на Паспорт приоритетного проекта «Современная цифровая образовательная среда в Российской Федерации» 1.

И, наконец, приказ Министерства образования и науки РФ от 23 августа 2017 г. № 816 «Об утверждении Порядка применения организациями, осуществляющими образовательную деятельность, электронного обучения, дистанционных образовательных технологий при реализации образовательных программ» ${ }^{2}$, который регулирует правила применения университетами электронного обучения, дистанционных образовательных технологий при реализации образовательных программ.

Существующие в достаточном количестве более «мелкие» правовые акты еще больше легитимизируют практику дистанционного обучения.

\section{Заключение}

Таким образом, дистанционное обучение - один из наиболее эффективных путей производства и накопления человеческого капитала, экономического и социального развития. Вопрос заключается сегодня лишь в том, насколько университеты готовы выступить провайдерами формального и неформального дистанционного образования, в какой мере ученые советы, кафедры, администрации вузов готовы включить в учебные планы цифровые онлайн- и офлайн-технологии.

В самое ближайшее время неформальное дистанционное обучение может стать эффективным средством воспитательной работы, которую в университетах никто не отменял. В этом видится один из действенных путей социализации не только студенческой, но других групп молодежи (возьмем, к примеру, те же блоговые коммуникации). Следует ожидать развития группового самообучения, особенно в рамках неформальных сетевых сообществ, общественных и религиозных объединений, вне зависимости от того, предусмотрена ли в их уставе информационно-образовательная и просветительская деятельность. В этих социально-политических процессах университеты могут занять важную нишу, которую им изначально отводило общество и которую они более или менее успешно осваивали всю свою историю.

При этом традиционное формальное образование остается, как всегда, эффективным средством вертикальной мобильности, поскольку данный социальный рынок контролируется старшими поколениями и делегированными от них полномочиями соответствующим институтам общества.

\footnotetext{
1 Паспорт приоритетного проекта «Современная цифровая образовательная среда в Российской Федерации» // Правительство России. URL: http://government.ru/media/files/8SiLmMBgjAN89vZbUUtmuF5IZYfTvOAG.pdf (дата обращения: 16.05.2020).

2 Приказ Министерства образования и науки РФ от 23 августа 2017 г. № 816 «Об утверждении Порядка применения организациями, осуществляющими образовательную деятельность, электронного обучения, дистанционных образовательных технологий при реализации образовательных программ» // Контур. Норматив. https://normativ.kontur.ru/document?moduleld=1\&documentld=300600 (дата обращения: 16.05.2020).
} 


\section{Ссылки / References}

1. Бороненко Т. А., Кайсина А. В., Федотова В. С. Диалог в дистанционном обучении // Высшее образование в России. 2017. № 8-9. С. 131-134.

2. Шуклина Е. А. Технологии самообразования: социологический аспект // Общественные науки и современность. 1999. № 5. С. 140-151.

3. Чехов Н. В. Народное образование в России с 60-х годов XIX века. М.: Книгоиздательство «Польза» В. Антик и К, 1912. 224 с.

4. Фертикова Д. О. Преимущества и недостатки дистанционного обучения // Международный журнал гуманитарных и естественных наук. 2017. № 11. С. 40-42.

5. Осиленкер Л. Б. Социально-экономические аспекты использования дистанционного обучения в высшей школе: автореф. дис. ... канд. экон. наук. М., 2006. 22 с.

6. Попов Д. И., Попова Е. Д., Федоренко Н. М. К вопросу о качестве дистанционного обучения // Вестник МГУП имени Ивана Федорова. 2016. № 1. С. 91-93.

7. Зборовский Г. Е., Амбарова П. А. Риски образовательной неуспешности учащейся молодежи // Социологический журнал. 2020. Том 26. № 2. С. 60-81.

8. Константиновский Д. Л. Неравенство и образование. Опыт социологических исследований жизненного старта российской молодежи (1960-е годы - начало 2000-х). М.: ЦСП, 2008. 552 с.

9. Huei-Chuan Wei, Sciprofile linkChien Chou. Online learning performance and satisfaction: do perceptions and readiness matter? // Distance Education. Vol. 41. P. 48-69. URL: https://www.scilit.net/article/a48b5781a1c8a623e9ff143e595d4296 (дата обращения: 15.05.2000).

10. Berg Gary A., Simonson M. Distance learning // Encyclopedia Britannica. 07.11.2018. URL: https://www.britannica.com/topic/distance-learning (дата обращения: 15.05.2020).

11. Непрерывное образование - стимул человеческого развития и фактор социальноэкономических неравенств. М.: ЦСПиМ, 2014. 433 с.

12. Faure E. Learning to Be: The World of Education Today and Tomorrow. Paris: UNESCO, 1972.

13. Connecting online students to their higher learning institution / S. Skelcher, D. Yang, J. Jesús Trespalacios, C. Snelson. // Distance Education. Vol. 41. P. 128-147. URL:

https://www.scilit.net/article/d5558489f2753f4d0301d8458c394336 (дата обращения: 15.05.2020).

14. Перова Ю. П. Технологии тестирования в дистанционном обучении // Доклады Томского государственного университета систем управления и радиоэлектроники. 2015. № 1. C. 138-141.

15. Усачева О. В., Черняков М. К. Оценка готовности вузов к цифровой образовательной среде // Высшее образование в России. 2020. № 5. С. 53-62.

16. Требования и рекомендации по разработке онлайн-курсов, публикуемых на национальной платформе открытого образования // Открытый Политех. URL: https://open.spbstu.ru/wp-content/uploads/2016/02/npoed_treb.pdf (дата обращения: 15.05.2020). 